\title{
Effects of dextran-40 on flap viability after modified radical mastectomy
}

\author{
Baris Dogu Yildiz MD¹, Barlas Sulu MD²
}

BD Yildiz, B Sulu. Effects of dextran-40 on flap viability after modified radical mastectomy. Can J Plast Surg 2013;21(2):83-86.

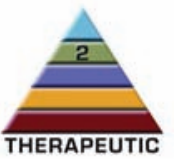

BACKGROUND: Postoperative management of patients after modified radical mastectomy has evolved over the past decades. In the early postoperative period, wound complication rates were reported to be as high as $60 \%$. Flap necrosis after modified radical mastectomy is a common problem encountered by surgeons. Various treatment strategies have been proposed in the literature but none have addressed the use of dextran-40.

OBJECTIVE: To determine whether dextran-40 infusion improves skin flap viability after modified radical mastectomy.

METHODS: Twenty-eight patients who underwent modified radical mastectomy were randomly assigned to receive dextran-40 or no dextran-40 intraoperatively after flap dissection. Patients were followed prospectively over a five-year period in a community hospital. The incidence of postmastectomy skin flap necrosis and prognosis of the necrotic area after dextran-40 infusion was observed.

RESULTS: Flap necrosis was observed in five (17.8\%) patients. Hypertension and diabetes mellitus were found to be risk factors for the development of flap necrosis $(\mathrm{P}<0.05)$. Flap thickness and tension on the flaps were found to be related to flap necrosis. Six of seven patients with flap perfusion problems (ecchymosis or necrosis) underwent dextran-40 treatment and healed without graft replacement.

CONCLUSIONS: Dextran-40 treatment did not affect development of flap necrosis. However, if necrosis had already developed, the necrotic area of the skin flaps improved with dextran-40 treatment.

Key Words: Breast cancer; Breast surgery; Flap circulation; Flap surgery; Mastectomy; Resection; Skin flap

$\mathrm{M}$ odified radical mastectomy still constitutes a significant portion of preferred methods for operable breast carcinomas despite the increasing use of breast-conserving techniques.

Postoperative management of patients after modified radical mastectomy has evolved over the past decades. In the early postoperative period, wound complications, including seroma, wound infection, wound necrosis and hematoma, and lymphedema rates were reported to be as high as $60 \%$ (1). Perioperative risk factors for wound complications developing after mastectomy have been well described in the literature (2).

A significant portion of efforts to decrease postoperative wound complications are directed toward minimizing operative blood loss and postoperative serum collection $(3,4)$. Furthermore, flap dissection techniques have been re-evaluated for minimizing wound complications encountered after modified radical mastectomy (5).

Flap necrosis is a well-known complication encountered after various types of breast surgery. The rate of flap necrosis is reported to be between 3\% and 32\% (6). Despite a sizable volume of surgical literature discussing probable causes of flap necrosis, the preferred classification method for necrosis or epidermolysis lacks objectivity $(7,8)$. Skin grafting of the necrotic area has been suggested as the sole treatment option in these studies.

\section{Les effets du dextran 40 sur la viabilité des lambeaux après une mastectomie radicale modifiée}

HISTORIQUE : La prise en charge postopératoire des patientes qui ont subi une mastectomie radicale modifiée a évolué depuis quelques décennies. Au début de la période postopératoire, le taux de complication des plaies peut atteindre les $60 \%$. La nécrose des lambeaux après une mastectomie radicale modifiée est un problème courant pour les chirurgiens. Diverses stratégies thérapeutiques sont proposées dans les publications, mais aucune n'a porté sur l'utilisation de dextran 40 .

OBJECTIF : Déterminer si l'injection de dextran 40 améliore la viabilité des lambeaux cutanés après une mastectomie radicale modifiée. MÉTHODOLOGIE : Vingt-huit patientes ayant subi une mastectomie radicale modifiée ont été réparties au hasard pour recevoir ou non du dextran 40 pendant l'opération, après la dissection des lambeaux. Elles ont subi un suivi prospectif de cinq ans dans un hôpital général. Les chercheurs ont évalué l'incidence de nécrose des lambeaux cutanés après une mastectomie et le pronostic de zone nécrosée après l'injection de dextran 40.

RÉSULTATS : Les chercheurs ont observé une nécrose des lambeaux chez cinq patientes (17,8 \%). L'hypertension et le diabète étaient des facteurs de risque $(P<0,05)$. L'épaisseur et la tension des lambeaux y étaient liées. Six des sept patientes présentant des problèmes de perfusion des lambeaux (ecchymose ou nécrose) ont subi un traitement au dextran 40 et ont guéri sans qu'il soit nécessaire de remplacer la greffe.

CONCLUSIONS : Le traitement au dextran 40 n'influait pas sur l'apparition d'une nécrose des lambeaux, mais en présence d'une nécrose, l'état de la zone nécrosée des lambeaux cutanés s'améliorait grâce au traitement au dextran 40 .

The present clinical research study aimed to investigate whether dextran-40 infusion decreased the rate of flap necrosis or improved prognosis after flap necrosis associated with modified radical mastectomy. Patient- and tumour-related factors were also evaluated.

\section{METHODS}

A total of 28 modified radical mastectomies were performed between August 1999 and January 2003. Fifteen of 28 patients received dextran-40 infusion (group A) and 13 patients were followed without additional treatment (group B). Informed written consent was obtained from each patient before enrollment in the study. The present study was conducted according to the guidelines in the Declaration of Helsinki, and all procedures involving human subjects/patients were approved by the hospital ethics commitee. Patients were randomized according to a computer program. None of the patients were excluded from the study before or during randomization.

All patients underwent unilateral mastectomy for noninflammatory breast carcinoma. A transverse oblique incision was preferred for mastectomy in all patients. The incision plane was marked with a skin marker pen before starting. Distances from the clavicle to the upper border of the incision, from the costal arch to the lower border of the incision, from the midline of the sternum to the medial end of the

${ }^{1}$ Department of Surgery, Ankara Numune Training Hospital, Ankara; ${ }^{2}$ Kafkas University Faculty of Medicine, General Surgery, Kars, Turkey Correspondence: Dr Baris Dogu Yildiz, Selanik cad 29/2 Kizilay 06650, Ankara, Turkey. Telephone 90-532-445-46-55,

fax 90-312-424-15-20, e-mail baris104@yahoo.com 
Figure 1) Necrotic area on skin flaps in patient 1 is shown. The photograph is processed by a software program in which the boundaries of necrosis and the entire flap area is marked

incision and from the midline of the axilla to the lateral end of incision were recorded in all patients. The upper and lower borders between the incision and the tumour mass were also recorded. Dissection of the flaps was performed using a cold blade. Flap thickness was measured at eight different points in both the superior and inferior flaps. The average thickness of each flap was calculated separately for each patient.

Following flap dissection, a test dose of dextran-40 (20 mL intravenously) was administered to the patients in group $\mathrm{A}$ for anaphylactic reaction. Dextran-40 infusion $(25 \mathrm{~mL} / \mathrm{h}$ for three days) was started thereafter in patients without an anaphylactic reaction. In patients with skin necrosis, dextran-40 infusion was extended up to five days.

Dissection of the pectoralis minor head was performed in each patient before axillary dissection. All patients had two closed suction drainage catheters placed at the time of surgery - one in the axillary region and the other beneath the skin flaps. After closing the skin incision, previously performed distance measurements were repeated and recorded. A compression dressing, which consisted of three $10 \mathrm{~cm}$ laparotomy pads, was held in place by a circumferential elastic adhesive bandage. The compression dressing remained in place until postoperative day 2 .

Surgeons observed and evaluated wound status and the amount of drainage daily. Flap appearance was recorded using a digital camera (Cybershot 4.0, Sony Corporation, Japan) on both anterior and lateral sides of the chest on postoperative days 2, 5 and 7, and more than three times daily in the presence of flap necrosis. Digital photograph files were transferred to a personal computer and dissection area and the area with perfusion problems (Figure 1) were marked using a software program (Corel Draw 10.0, Corel Corporation, Canada) (Figure 2). Prepared images were stored in a computer for analysis with a software program customized for the present study. With this program, necrotic or ecchymotic area was defined as the percentage of dissection area.

Drains were removed when the drainage volume fell to $<50 \mathrm{~mL}$ per day. If collection was observed after removal of the drain, aspiration and daily examination were performed until seroma subsided. The total volume of drainage including all postoperative drainage until drain removal was recorded. The total number of days with a drain and the number and the amount of seroma aspirations after drain removal were also recorded.

The groups were compared with respect to age, weight, nodal status and size of the primary tumour. The incidence of seromas, flap necrosis, wound infection, arm edema and shoulder disability was recorded.

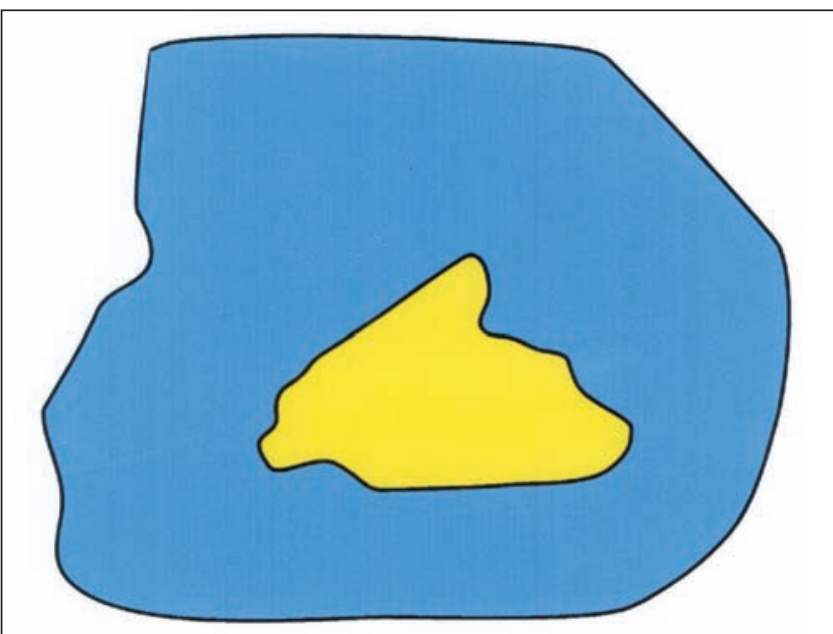

Figure 2) The software program assigns two different colours (blue and yellow) to necrosis and the entire flap area, it then calculates per cent necrosis

Due to the limited number of patients in the study group, values are expressed as median, minimum and maximum. The number of events in each arm of the study were compared using the Mann-Whitney U test and the two-tailed Fischer's exact probability test.

\section{RESULTS}

Patient age ranged between 39 and 74 years. Patient characteristics of the study groups are summarized in Table 1 .

Table 2 presents flap features recorded during the operation. Each parameter was comparable in both groups. Median values of incisionclavicle and incision-costal arch measurements showed increases compared with preincision values. Lengthening of the distal flap (flap below the incision) was greater than the proximal flap (flap above the incision) in most of the cases. Distal flaps were generally thicker than proximal flaps. Distances from the lateral end of the incision to the midaxillary line and from the medial end of the incision to the midline of the sternum were not affected by the operation. The differences in these changes were not statistically significant. No skin graft replacement was required at the end of the operations.

The operative and postoperative variables are summarized in Table 3. Dextran-40 infusion did not affect operation time, amount of blood loss and drainage (axillary and skin flaps) from the operative field $(\mathrm{P}=0.215, \mathrm{P}=0.817, \mathrm{P}=0.327$ and $\mathrm{P}=0.278$, respectively $)$. The overall incidence of surgical complications was $42.8 \%$ (12 of 28 ). Of the seven patients in group A with skin flap ecchymosis, three developed necrosis. Ecchymosis was observed in two patients in group B and progressed to skin necrosis within one week. Patients with necrosis in the study group had at least one chronic disease (hypertension, diabetes or coronary artery disease) (Table 4). Four (80\%) of the five patients with a flap necrosis had a history of hypertension compared with two $(9.5 \%)$ of the 21 patients without flap necrosis after mastectomy $(\mathrm{P}<0.005)$. A history of diabetes was found in three $(60 \%)$ of the five patients with flap necrosis compared with two $(8.7 \%)$ of the 23 patients without flap necrosis $(\mathrm{P}<0.05)$. The maximum tumour diameter of patients with necrosis was $\geq 3 \mathrm{~cm}$; however, no significant difference was found compared with uncomplicated cases. The incision-costal arch distance was significantly lengthened in patients with necrotic skin compared with the others $(\mathrm{P}<0.05)$. The average thickness of both proximal and distal flaps in patients with flap necrosis was lower than the median values of both groups except in patient 5 . Necrotic areas were in close proximity to the incision site and invaded both proximal and distal skin flaps in all patients with skin flap necrosis. Two patients with skin flap necrosis in the dextran-40 infusion group healed completely without skin grafting. One patient in group A and two patients in group B were treated with skin grafting (Table 4). None of the patients in group A experienced dextran-40-related complications. 
TABLE 1

Patient and tumour characteristics

\begin{tabular}{|c|c|c|c|}
\hline \multirow[b]{2}{*}{ Variable } & \multicolumn{2}{|c|}{ Group* } & \multirow[b]{2}{*}{$\mathbf{P}$} \\
\hline & $A(n=15)$ & $B(n=13)$ & \\
\hline Age, years & $54.5(39-74)$ & $48.5(40-71)$ & 0.661 \\
\hline Body mass index, $\mathrm{kg} / \mathrm{m}^{2}$ & $25.6(20.4-43.1)$ & $25.5(20.1-40.1)$ & 0.797 \\
\hline Maximum tumour diameter, $\mathrm{cm}$ & $3(1-6)$ & $3(1-5)$ & 0.792 \\
\hline \multicolumn{4}{|l|}{ Tumour staging of patients, $n$} \\
\hline Stage 0 & 2 (DCIS) & 1 (DCIS) & \\
\hline Stage 1 & 2 & 1 & \\
\hline Stage $2 a$ & 2 & 3 & \\
\hline Stage $2 b$ & 3 & 1 & \\
\hline Stage $3 a$ & 5 & 6 & \\
\hline Stage $3 b$ & 1 & 1 & \\
\hline \multicolumn{4}{|l|}{ Preoperative biopsy, n } \\
\hline Needle biopsy & 1 & 1 & \\
\hline Open biopsy (incision) & 6 & 5 & \\
\hline Open biopsy (excision) & 8 & 7 & \\
\hline \multicolumn{4}{|l|}{ Tumour location, $\mathbf{n}$} \\
\hline Tumour limited to one quadrant & 14 & 12 & \\
\hline Upper outer quadrant & 11 & 7 & \\
\hline Upper inner quadrant & 1 & 2 & \\
\hline Lower outer quadrant & 1 & 0 & \\
\hline Lower inner quadrant & 1 & 3 & \\
\hline $\begin{array}{l}\text { Tumour invaded more than } \\
\text { one quadrant }\end{array}$ & 1 & 1 & \\
\hline
\end{tabular}

Data presented as median (minimum-maximum) unless otherwise indicated. ${ }^{*}$ Group A patients underwent dextran-40 treatment, group B patients did not. DCIS Ductal carcinoma in situ

\section{DISCUSSION}

A commonly recognized complication of breast surgery is necrosis of skin flaps or skin margins. Risk factors for flap necrosis were examined in controlled or uncontrolled series. Patient-related factors including smoking history and obesity are well investigated in various studies and both have been found to affect the development of necrosis (9). Our study also confirmed this relationship. Tumour-related factors affecting the development of flap necrosis include stage and pathology of the tumour, preoperative chemotherapy and preoperative radiotherapy $(10,11)$. Locally advanced (stage $3 a$ and $3 b$ ) tumours are generally associated with tumour masses of a large diameter, skin ulcerations, fixations, inflammation and satellite nodules. Thus, achieving adequate tumour-free margins may ultimately lead to flap necrosis secondary to excessive breast skin excision (12). Thirteen (46\%) of the 28 patients in our study group had stage $3 a$ or $3 b$ tumours. Skin invasion was observed in one patient (patient 5). Excessive lengthening of skin flaps for skin closure may create tension on flaps in these patients. As expected, incision-costal arch distance was increased significantly from the average length in all patients with flap necrosis in our study group.

Increased rates of wound complications, including flap necrosis, are found in patients receiving preoperative chemotherapy and/or radiotherapy $(13,14)$. In contrast to these reports, no significant relationship between preoperative chemotherapy and/or radiotherapy and wound complications seen after mastectomy was demonstrated in other studies (2). In our study group, only one patient received preoperative chemotherapy and was discharged without complications.

Factors related to surgical technique have been evaluated from different perspectives. Clinical trials with electrocautery and laser scalpel dissection did not demonstrate differences in flap necrosis rates compared with scalpel dissections (15). In a recent study, satisfactory results with harmonic scalpel were reported (16). Our preferred method for flap dissection in modified radical mastectomy is the scalpel technique. Despite the absence of thermal injury using the scalpel technique, flap necrosis was observed in our series (17.8\%).
TABLE 2

Thickness and lengths measured before and after mastectomy

\begin{tabular}{lccc}
\hline & \multicolumn{2}{c}{ Group*$^{*}$} & \\
\cline { 2 - 3 } & $\mathbf{A}(\mathbf{n}=\mathbf{1 5})$ & $\mathbf{B}(\mathbf{n}=\mathbf{1 3})$ & $\mathbf{P}$ \\
\hline Thickness of flaps, cm & & & \\
$\quad$ Proximal flap & $0.85(0.5-1.7)$ & $1(0.6-1.5)$ & 0.268 \\
$\quad$ Distal flap & $1(0.6-2)$ & $1.3(0.7-2)$ & 0.102 \\
Change in flap lengths after closure, cm & & \\
$\quad$ Proximal flap & $1(0.5-2)$ & $1(1-2)$ & 0.855 \\
$\quad$ Distal flap & $3.5(2-6)$ & $3(1.5-4.5)$ & 0.958 \\
\hline
\end{tabular}

Data presented as median (minimum-maximum), unless otherwise indicated. *Group A patients underwent dextran-40 treatment, group B patients did not

TABLE 3

Comparison of operative and postoperative variables in 28 patients with (group A) and without (group B) dextran-40 treatment

\begin{tabular}{lccc}
\hline & \multicolumn{2}{c}{ Group } & \\
\cline { 2 - 3 } & A (n=15) & B (n=13) & P \\
\hline Operative time, min & $162.5(120-230)$ & $150(130-190)$ & 0.215 \\
Blood loss, mL & $325(200-410)$ & $305(240-400)$ & 0.817 \\
Operative complications, $\mathrm{n}$ & & & \\
$\quad$ Thoracodorsal nerve injury & 1 & - & \\
$\quad$ Brachial plexus injury & - & 1 & \\
Drainage, mL & & & \\
$\quad$ Axillary & $350(260-640)$ & $325(190-600)$ & 0.327 \\
$\quad$ Skin flaps & $230(170-450)$ & $200(160-300)$ & 0.278 \\
Seroma, $\mathrm{n}$ & 2 & 1 & \\
Flap viability problems, $\mathrm{n}$ & 7 & 2 & \\
$\quad$ Ecchymosis & 7 & 2 & \\
$\quad$ Necrosis & 3 & 2 & \\
Infection, $\mathrm{n}$ & 0 & 1 & \\
\hline
\end{tabular}

Data presented as median (minimum-maximum) unless otherwise indicated

In addition to tension on the flaps after skin closure, flap thickness plays a definitive role in the development of necrosis. Ideally, flap thickness should be $7 \mathrm{~mm}$ to $8 \mathrm{~mm}$ and include skin and tela subcutanea (17). The average thickness of skin flaps in our study group was slightly greater than suggested. However, four of the five patients with flap necrosis had thinner skin flaps than the average of the study group.

Discrepancies in classification method for skin necrosis are present in the literature. Hoefer et al (7) divided flap necrosis into two categories: minor degree of marginal flap necrosis $\left(<2 \mathrm{~cm}^{2}\right)$, which requires no specific therapy; and significant wound slough that requires skin grafting. More detailed definition of flap necrosis is reported by Forouhi et al (8), who described superficial sloughing or edge necrosis $<1 \mathrm{~cm}$ in diameter as minor necrosis, and full thickness necrosis requiring skin grafting as a major necrosis. In both of these studies and in other series, limited data regarding objective description of the necrotic area have been reported. With the assistance of a digital camera, we followed-up flap viability in an objective manner for each patient. The necrotic area on skin flaps was calculated using a specially developed software program, and the width of the necrotic area was expressed as the percentage of the dissection area. With this method, the width and severity of the necrotic area were determined and expressed more objectively compared with previous classification methods.

The suggested treatment for flap necrosis is debridement and, occasionally, application of split-thickness skin grafts (18). In one study, topical administration of dimethylsulfoxide (DMSO) was used for prophylaxis against skin flap necrosis (19). However, there are some doubts regarding DMSO toxicity and the measurement of necrotic area in that study. Moreover, frequent application of DMSO on flaps also added some difficulties to its use. 
TABLE 4

Characteristics of patients with flap skin necrosis

\begin{tabular}{|c|c|c|c|c|c|}
\hline & \multicolumn{5}{|c|}{ Patient (group*) } \\
\hline & $1(\mathrm{~A})$ & $2(A)$ & $3(A)$ & $4(B)$ & $5(B)$ \\
\hline Age, years & 74 & 58 & 60 & 40 & 52 \\
\hline Body mass index, $\mathrm{kg} / \mathrm{m}^{2}$ & 34.5 & 24.7 & 30.8 & 24.6 & 28.2 \\
\hline Chronic illness & HT, DM & HT, DM & HT, CAD & DM & HT \\
\hline $\begin{array}{l}\text { Maximum tumour } \\
\text { diameter, } \mathrm{cm}\end{array}$ & 4 & 3 & 4 & 3 & 5 \\
\hline \multicolumn{6}{|c|}{ Mean change in flap length, $\mathrm{cm}$} \\
\hline Proximal flap & 0.5 & 1 & 2 & 1 & 1.5 \\
\hline Distal flap & 5 & 5 & 6 & 3 & 5 \\
\hline \multicolumn{6}{|l|}{ Mean flap thickness, $\mathrm{cm}$} \\
\hline Proximal flap & 0.6 & 0.7 & 0.6 & 0.9 & 1 \\
\hline Distal flap & 0.7 & 0.8 & 0.8 & 0.9 & 1.5 \\
\hline \multicolumn{6}{|c|}{ Necrosis/dissection area, \% } \\
\hline At day 2 & 13.65 & 11.97 & 4.25 & 15.33 & 14.85 \\
\hline At day 5 & 6.21 & 7.11 & 1.34 & 15.24 & 14.83 \\
\hline Skin grafting area, \% & 6.14 & $\begin{array}{l}\text { No graft } \\
\text { required }\end{array}$ & $\begin{array}{l}\text { No graft } \\
\text { required }\end{array}$ & 15.20 & 14.73 \\
\hline
\end{tabular}

*Patients in group A were treated with dextran-40, patients in group $B$ were not. CAD Coronary artery disease; DM Diabetes mellitus; HT Hypertension

\section{REFERENCES}

1. Ashikari RH. Modified radical mastectomy. Surg Clin North Am 1984;64:1095-102.

2. Sauter ER, Eisenberg BL, Hoffman JP, et al. Postmastectomy morbidity after combination preoperative irradiation and chemotherapy for locally advanced breast cancer. World J Surg 1993;17:237-42.

3. Woodworth PA, McBoyle MF, Helmer SD, Beamer RL. Seroma formation after breast cancer surgery: Incidence and predicting factors. Am Surg 2000;66:444-51.

4. O'Hea BJ, Ho MN, Petrek JA. External compression dressing versus standard dressing after axillary lymphadenectomy. Am J Surg 1999; 177:450-3.

5. Staradub VL, Morrow M. Modified radical mastectomy with knife technique. Arch Surg 2002;137:105-10.

6. Larson DL, Basir Z, Bruce T. Is oncologic safety compatible with a predictably viable mastectomy skin flap? Plast Reconstr Surg 2011;127:27-33.

7. Hoefer RA Jr, DuBois JJ, Ostrow LB, Silver LF. Wound complications following modified radical mastectomy: An analysis of perioperative factors. J Am Osteopath Assoc 1990;90:47-53.

8. Forouhi HP, Dixon JM, Leonard RCF, Chetty U. Prospective randomized study of surgical morbidity following primary systemic therapy for breast cancer. Br J Surg 1995:82:79-82.

9. Chang DW, Reece GP, Wang B, et al. Effects of smoking on complications in patients undergoing free TRAM flap breast reconstruction. Plast Reconstr Surg 2000:105:2374-80.

10. King TA, Bolton JS, Kuske RR, Fuhrman GM, Scroggins TG, Jiang XZ. Long-term results of wide-field brachytherapy as the sole method of radiation therapy after segmental mastectomy for $\mathrm{T}($ is $, 1,2)$ breast cancer. Am J Surg 2000;180:299-304.

11. Petit J, Rietjens M, Garusi C. Breast reconstructive techniques in cancer patients: Which ones, when to apply, which immediate and long term risks? Crit Rev Oncol Hematol 2001;38:231-9.

12. Bland KI, Palin WE, von Fraunhofer JA, Morris RR, Adcock RA, Tobin GR II. Experimental and clinical observations of the effects of cytotoxic chemotherapeutic drugs on wound healing. Ann Surg 1984;199:782-90.

13. Badr el Din A, Coibion M, Guenier C, et al. Local postoperative morbidity following pre-operative irradiation in locally advanced breast cancer. Eur J Surg Oncol 1989;15:486-9.

14. Furey PC, MacGillivray DC, Castiglione CL, Allen L. Wound complications in patients receiving adjuvant chemotherapy
Dextran has been used as a standard antithrombotic regimen for free-flap surgery or to improve tissue survival in ischemic skin and muscle flaps $(20,21)$. The efficacy of different dextran regimens on flap survival has been reported in the literature $(22,23)$. In our protocol, dextran-40 treatment was started perioperatively and continued until $72 \mathrm{~h}$ after the operation in cases without necrosis and up to five days after the operation in cases with skin flap necrosis. With this treatment protocol, there was no difference in blood loss, operative time and drainage from the operation site compared with patients who did not receive dextran infusion. Improvement of flap necrosis area was observed in all three patients treated with dextran-40.

Dextran derivatives are markedly allergic compounds that may cause adverse reactions ranging from rash to anaphylactic shock (24). In addition, severe pulmonary edema related to dextran infusion may progress into adult respiratory distress syndrome $(25,26)$. However, there were no dextran infusion-related complications in our study.

Our data suggest that dextran-40 infusion helps to improve the outcome of the necrotic area in patients with postmastectomy flap necrosis. In addition to effects of dextran therapy, our computerized surveillance method for necrotic area may provide new horizons to postoperative care in breast surgery. Although the use of dextran-40 for flap necrosis is a potentially promising research avenue, the present post hoc experience from our centre is an inadequate way to fully evaluate its efficacy and a true prospective study design is required.

after mastectomy and immediate breast reconstruction. J Surg Oncol 1994;55:194-7.

15. Sheen-Chen SM, Chou FF. A comparison between scalpel and electrocautery in modified radical mastectomy. Eur J Surg 1993;159:457-9.

16. Deo SV, Shukla NK, Asthana S, Niranjan B, Srinivas G. A comparative study of modified radical mastectomy using harmonic scalpel and electrocautery. Singapore Med J 2002;43:226-8.

17. Torresan RZ, dos Santos CC, Okamura H, Alvarenga M. Evaluation of residual glandular tissue after skin-sparing mastectomies. Ann Surg Oncol 2005;12:1037-44.

18. Newman MI, Samson MC, Tamburrino JF, Swartz KA. Intraoperative laser-assisted indocyanine green angiography for the evaluation of mastectomy flaps in immediate breast reconstruction. J Reconstr Microsurg 2010;26:487-92.

19. Rand-Luby L, Pommier RF, Williams ST, Woltering EA, Small KA, Fletcher WS. Improved outcome of surgical flaps treated with topical dimethylsulfoxide. Ann Surg 1996;224:583-90.

20. Glicksman A, Ferder M, Casale P, Posner J, Kim R, Strauch B. 1457 years of microsurgical experience. Plast Reconstr Surg 1997; 100:355-63.

21. Steinbauer M, Harris AG, Messmer K. Effects of dextran on microvascular ischemia-reperfusion injury in striated muscle. Am J Physiol 1997;272:H1710-H1716.

22. Wolfort SF, Angel MF, Knight KR, Amiss LR, Morgan RF. The beneficial effect of dextran on anastomotic patency and flap survival in a strongly thrombogenic model. J Reconstr Microsurg 1992;8:375-8.

23. Riberti C, Costa P, Lefevre JC, Chassagne JF. Clinical experience with the combination of dextran 40 , dihydroergotoxine, lidocaine in intravenous perfusion in the prevention of postoperative ischemia of skin flaps. Minerva Chir 1984;39:819-23.

24. Paul JA. A prospective study of dextran-induced anaphylactic reactions in 5745 patients. Anaesth Intensive Care 1987;15:163.

25. Hein KD, Wechsler ME, Schwartzstein RM, Morris DJ. The adult respiratory distress syndrome after dextran infusion as an antithrombotic agent in free TRAM flap breast reconstruction. Plast Reconstr Surg 1999;103:1706-8.

26. Demirkan F, Unal S, Arslan E, Calikoğlu M, Kandemir O. Severe pulmonary edema related to dextran 40 . Ann Plast Surg 2002;49:221-2. 